\title{
Exercise Following Bariatric Surgery: Systematic Review
}

\author{
Masha Livhits • Cheryl Mercado • Irina Yermilov • \\ Janak A. Parikh • Erik Dutson • Amir Mehran • \\ Clifford Y. Ko • Melinda Maggard Gibbons
}

Received: 20 November 2009 / Accepted: 28 January 2010 /Published online: 24 February 2010

(C) The Author(s) 2010. This article is published with open access at Springerlink.com

\begin{abstract}
The contribution of physical activity on the degree of weight loss following bariatric surgery is unclear. To determine impact of exercise on postoperative weight loss. Medline search (1988-2009) was completed using MeSH terms including bariatric procedures and a spectrum of patient factors with potential relationship to weight loss outcomes. Of the 934 screened articles, 14 reported on exercise and weight loss outcomes. The most commonly used instruments to measure activity level were the Baecke Physical Activity Questionnaire, the International Physical Activity Questionnaire, and a variety of self-made questionnaires. The definition of an active patient varied but generally required a minimum of $30 \mathrm{~min}$ of exercise at least 3 days per week. Thirteen articles reported on exercise and degree of postoperative weight loss $(n=4,108$ patients). Eleven articles found a positive association of
\end{abstract}

M. Livhits $\cdot$ C. Mercado $\cdot$ I. Yermilov J. A. Parikh $\cdot$ E. Dutson $\cdot$

A. Mehran • C. Y. Ko - M. M. Gibbons

Department of Surgery,

David Geffen School of Medicine at UCLA,

10833 LeConte Ave, 72-215 CHS,

Los Angeles, CA 90095, USA

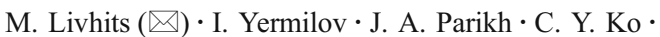

M. M. Gibbons

Department of Surgery,

VA Greater Los Angeles Healthcare System,

11301 Wilshire Blvd,

Los Angeles, CA 90073, USA

e-mail: mlivhits@mednet.ucla.edu

M. M. Gibbons

Department of Surgery, Olive View-UCLA,

14445 Olive View Dr, Rm 2B-156,

Sylmar, CA 91342, USA exercise on postoperative weight loss, and two did not. Meta-analysis of three studies revealed a significant increase in 1-year postoperative weight loss (mean difference $=4.2 \%$ total body mass index (BMI) loss, 95\% confidence interval (CI; 0.26-8.11)) for patients who exercise postoperatively. Exercise following bariatric surgery appears to be associated with a greater weight loss of over $4 \%$ of BMI. While a causal relationship cannot be established with observational data, this finding supports the continued efforts to encourage and support patients' involvement in post-surgery exercise. Further research is necessary to determine the recommended activity guidelines for this patient population.

Keywords Bariatric surgery $\cdot$ Weight loss $\cdot$ Exercise

\section{Introduction}

Morbid obesity is a major contributor to a wide variety of disease states including diabetes mellitus, coronary artery disease, and sleep apnea. Obesity, generally defined as a body mass index (BMI) greater than $30 \mathrm{~kg} / \mathrm{m}^{2}$, increases the risk of all-cause death [1]. Due to the high prevalence of overweight (BMI between 25 and $30 \mathrm{~kg} / \mathrm{m}^{2}$ ) and obesity, interventions such as diet and exercise to promote weight loss have become increasingly important to reduce morbidity in the general population. The benefits of exercise include increasing energy expenditure and lean body mass while contributing to fat loss, reducing obesity-related complications, and improving self-esteem and depression [2]. Exercise also improves cardiopulmonary fitness, which may reduce mortality from cardiovascular disease [3].

The literature varies on the magnitude of weight loss that can be achieved by exercise and the level of activity 
necessary to achieve it. A negative energy balance of 500 calories per day results in 1 pound of weight loss per week [4]. To achieve this with exercise requires the equivalent of $1 \mathrm{~h} /$ day of aerobic exercise. Walking is one of the easiest and safest ways to establish an exercise program for overweight patients, with 70,000 to 100,000 steps per week necessary to help weight loss. Over a 12 -week period, studies have found that overweight patients lose $2.5 \%$ to $8 \%$ of their body weight through exercise alone $[5,6]$. Long-term maintenance of physical activity (contributing to energy expenditure of 1,500 to 2,000 kilocalories (kcal) per week) has been found to decrease weight gain [7]. The NHLBI Obesity Education Initiative Expert and the US Preventive Services Task Force developed guidelines establishing the amount of physical activity necessary to promote weight loss and reduce comorbidities. They generally consist of at least $30 \mathrm{~min}$ of aerobic activity daily, amounting to an energy expenditure of 2,500 to $3,500 \mathrm{kcal}$ per week [8].

Exercise has been postulated to improve weight loss after bariatric surgery. However, even moderate physical activity is often difficult for morbidly obese patients due to comorbidities such as osteoarthritis and asthma. Patients who have undergone bariatric surgery are forced to make dietary changes due to the restrictive and/or malabsorptive changes of the operation. The role of physical activity in contributing to weight loss is less clear, as patients are already forced to significantly decrease their caloric intake. Recommendations regarding physical activity are more difficult to enforce. It is critical to evaluate whether exercise improves weight loss outcomes to determine if this modality should be mandated as part of the standard postoperative guidelines.

This systematic review analyzes the evidence regarding physical activity following bariatric surgery. The main outcome of interest is postoperative weight loss, but additional information regarding the instruments used to measure exercise and the definition of physical activity is also assessed.

\section{Materials and Methods}

\section{Identification and Selection of Studies}

This study is part of a larger systematic review examining patient factors related to postoperative weight loss after bariatric surgery. Relevant studies evaluating exercise were identified by searching MEDLINE (1/1/1988 to 3/4/2009) under the search words (("Bariatric Surgery"[Mesh/NoExp] OR "weight loss surgery" OR "obesity surgery" OR "weight reduction surgery" OR "Biliopancreatic Diversion"[Mesh] OR "Duodenal switch"OR "laparoscopic band" OR "lap band" OR "gastric band" OR "Gastric Bypass"[Mesh] OR "Gastroplasty"[Mesh] OR "gastric sleeve" OR "sleeve gastrectomy") AND "Obesity"[Mesh]) AND ("Physical Therapy Modalities"[Mesh] OR "Physical Therapy (Specialty)"[Mesh] OR "Exercise Movement Techniques"[Mesh] OR "Complementary Therapies" [Mesh] OR "physiotherapy" OR "physio therapy" OR "therapeutic exercise" OR "Occupational Therapy"[Mesh] OR "Exercise"[Mesh] OR "Exercise therapy"[Mesh]). We manually mined reference lists of the retrieved studies to identify additional relevant publications.

The full text of the articles was evaluated with a standardized article screener by two of the researchers. The selection criteria included studies published in English with patients over the age of 18 years (studies with patients both over and under 18 years old were accepted) who underwent bariatric surgery (open or laparoscopic gastric bypass, laparoscopic gastric banding, biliopancreatic diversion, vertical-banded gastroplasty, or gastric sleeve; other bariatric procedures or not bariatric surgery were excluded). Accepted study designs included case series/cohort, case control, and randomized control trials; studies with a sample size of less than ten were excluded. Studies that did not report on exercise and postoperative weight loss were excluded.

\section{Data Extraction}

Data were abstracted from each study by two physicians. The following relevant information was recorded: study design, type of operation, baseline patient demographics, number of patients and definition of physical activity or exercise, and degree of postoperative weight loss.

\section{Meta-analysis}

A meta-analysis was performed to assess the combined association of postoperative exercise on 12-month postoperative weight loss, calculated as percent total BMI loss. Studies were included if they reported 12-month weight loss for patients who exercised versus patients who did not exercise as \% BMI change or BMI points lost, resulting in three studies included in the meta-analysis. Patients in the exercise group were defined as meeting a certain threshold of activity, which differed per study. The mean difference method in REVMAN (version 5.0.22) was used [9]. A random effects model was used to calculate mean differences, 95\% confidence intervals (CIs), a combined overall association with $P$ value, and the $P$ value for testing heterogeneity $(P<0.1$ was considered significant). When the standard deviation (SD) was not available, as was the case for two studies, it was estimated using the mean SD from other studies. 


\section{Results}

\section{Description of the Selected Studies}

The search strategy yielded 164 studies on exercise and weight loss after bariatric surgery, 13 fulfilled the criteria for this review (Fig. 1). Excluded articles did not report on a potential association between exercise and postoperative weight loss. Two studies were from the same research group but had different study designs and patient groups, and so they were considered as separate studies [10, 11]. The 13 studies report on 4,108 patients; mean age ranges from 42 to 46 years, and mean follow-up interval ranges from 12 to 27 months. All studies have patient samples with a majority of female patients except Dixon et al [12], and baseline BMI in the 37 to $58 \mathrm{~kg} / \mathrm{m}^{2}$ range (Table 1). The majority of the studies report on either open or laparoscopic Roux-en-Y gastric bypass (RYGB) or laparoscopic adjustable gastric banding (LAGB), though Hernandez-Estefania et al. enrolled patients undergoing vertical-banded gastroplasty (VBG) [13] and Metcalf et al. included patients who underwent a duodenal switch (DS) operation [14].

Dixon et al. is the only randomized control trial, comparing patients randomized to LAGB or conventional therapy (but patients were not randomized with respect to exercise). Both groups received counseling regarding nutrition, physical activity, and if applicable, diabetes management, and the latter group had options for low calorie diets or pharmaceutical agents. All participants were separated into two groups based on amount of weekly exercise. Three of the studies are prospective cohorts, two

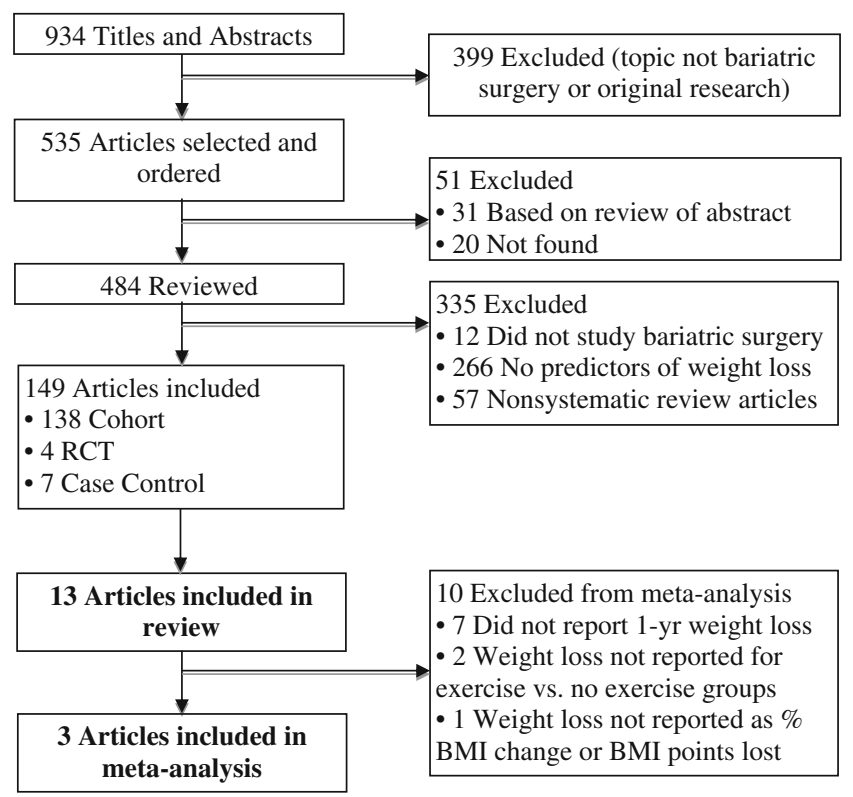

Fig. 1 Flow diagram of included and excluded studies for review of which compare a group of active patients versus a group of inactive patients after bariatric surgery $[13,15]$. The third looks at physical activity both pre- and postoperatively and separates patients into three groups: inactive pre- and postoperatively, inactive preoperatively and active postoperatively, and active pre- and postoperatively [11].

The remaining eight studies are retrospective cohorts, two compare an exercise versus no exercise group after bariatric surgery $[10,14]$. The other studies did not separate patients into exercise groups, but rather report a correlation between postoperative physical activity and degree of weight loss for the entire patient cohort [16-20]. Cook et al. groups patients based on success or failure to lose weight after RYGB, and measures exercise frequency in the two groups [21].

Due to the search strategy, all of the studies have postoperative weight loss as their primary outcome. The length of follow-up varies from 12 to 27 months (mean follow-up 18.9 months). Weight loss is generally reported for the different groups as percentage of excess weight loss (\% EWL), though some studies report the actual weight lost in kilograms while others report the change in BMI.

\section{Measurement of Physical Activity}

Four of the studies used validated instruments to assess the level of physical activity performed by the participants. This includes the Baecke Physical Activity Questionnaire, which was validated in obese non-surgical patients [22] and also in adult females with hip disorders, including those status post total hip arthroplasty [23]. It has a total of 16 questions classified into three domains: work, sports, and non-sports leisure activity [24]. Each domain has several questions scored on a five-point Likert scale, ranging from never to always or very often, and the time frame included is the past year. Both Colles et al. and Larsen et al. use portions of the Baecke Questionnaire (Table 2). Bond et al. [11] utilizes the International Physical Activity Questionnaire short form to measure physical activity both pre- and postoperatively. This survey has been validated in obese non-surgical patients [25] and in normal adult populations internationally [26]. This self-administered survey assesses walking and moderate or vigorous activities in everyday life, as measured for the past 7 days [26].

Nine studies only utilize self-developed surveys to assess physical activity. Several define the "active" or "exercise" group as those patients who did some level of activity for at least 30 minutes, at least three times per week (Table 2). Bueter et al. measures the frequency with which patients performed endurance sports (e.g. swimming, running, and cycling), while Bond et al. [10] accepts participation in physical activity if patients reported any aerobic activity at any of their office visits through 2 years after surgery. 
Table 1 Baseline characteristics of studies included in the review

\begin{tabular}{|c|c|c|c|c|c|c|}
\hline Author (year) & Study design & Operation & Number & MeanaAge, years (SD) & $\begin{array}{l}\text { Gender } \\
\text { (\% female) }\end{array}$ & Baseline BMI (SD) \\
\hline Larsen [16] & Retrospective cohort & Lap RYGB & 157 & $40(7.9)$ & 91.7 & $45.5(5.7)$ \\
\hline Bueter [20] & Retrospective cohort & Lap RYGB & 85 & 40 & 81 & 49 \\
\hline Colles [33] & Prospective cohort & Lap RYGB & 129 & $45.2(11.5)$ & 80 & $44.3(6.8)$ \\
\hline Cook [21] & Retrospective cohort & RYGB $^{\mathrm{a}}$ & 100 & - & 95 & - \\
\hline Bond [10] & Retrospective cohort & RYGB $^{\mathrm{a}}$ & 1,585 & $40.4(10)$ & 83 & $49.8(7.4)$ \\
\hline Latner [17] & Retrospective cohort & RYGB $^{\mathrm{a}}$ & 65 & 39.5 & 100 & $54.1(10.2)$ \\
\hline Silver [18] & Retrospective cohort & RYGB $^{\mathrm{a}}$ & 140 & $45.2(9.9)$ & 89 & $49.8(7.9)$ \\
\hline Wolfe [19] & Retrospective cohort & RYGB $^{\mathrm{a}}$ & 194 & $42.1(10.4)$ & 88 & $\begin{array}{l}\text { M: } 58.3(12.4) \\
\text { F: } 51.8(10.7)\end{array}$ \\
\hline Bond [11] & Prospective cohort & RYGB $^{\mathrm{a}}$ & $\begin{array}{r}39^{\mathrm{c}} \\
83 \\
68\end{array}$ & $\begin{array}{l}46(10)^{\mathrm{c}} \\
43.7(11.1) \\
41.5(10.7)\end{array}$ & $\begin{array}{l}90^{\mathrm{c}} \\
80 \\
82\end{array}$ & $\begin{array}{l}50.5(8.4)^{\mathrm{c}} \\
49.8(7) \\
49.8(8.7)\end{array}$ \\
\hline Chevallier [15] & Prospective cohort & LAGB & 1,236 & - & - & - \\
\hline Dixon [12] & Randomized control trial & $\begin{array}{l}\text { LAGB } \\
\text { Medical therapy }\end{array}$ & $\begin{array}{l}30 \\
30\end{array}$ & $\begin{array}{l}46.6(7.4) \\
47.1(8.7)\end{array}$ & $\begin{array}{l}50 \\
57\end{array}$ & $\begin{array}{l}37(2.7) \\
37.2(2.5)\end{array}$ \\
\hline Hernandez-Estefania [13] & Prospective cohort & VBG & 67 & $20-60^{\mathrm{b}}$ & 84 & $47.5(7.7)$ \\
\hline Metcalf [14] & Retrospective cohort & Duodenal switch & 100 & $27-63^{b}$ & 86 & - \\
\hline
\end{tabular}

$R Y G B$ roux-en-Y gastric bypass, lap laparoscopic, $V B G$ vertical-banded gastroplasty, $L A G B$ laparoscopic adjustable gastric banding, $M$ males, $F$ females

${ }^{a}$ Not stated if laparoscopic or open technique

${ }^{\mathrm{b}}$ Age range (no means or standard deviations included in article)

${ }^{\mathrm{c}}$ Data listed in order of groups (preoperative/postoperative): inactive/inactive, inactive/active, active/active

\section{Postoperative Weight Loss: Systematic Review}

Eleven studies report a beneficial association of exercise on postoperative weight loss (Table 3). Of these, six studies examine weight loss 12 months after bariatric surgery. Bond et al. [11] and Hernandez-Estefania et al. both found a positive correlation between postoperative physical activity and the degree of weight loss at 12 months, as well as a significant difference in weight loss between the active and inactive groups. Chevallier et al. has similar results, with patients who exercised having a $60 \%$ lower odds ratio of weight loss failure. Cook et al. comment that $77 \%$ of patients with successful weight loss (defined as greater than $74 \%$ of weight loss at 1 year) exercised postoperatively. Colles et al. report a correlation between weight loss and different indices of the Baecke Physical Activity Questionnaire, and found that a higher number of barriers to physical activity impede weight loss at 12 months $(r=-0.2, P=0.021)$. Metcalf et al. is the only study with inconclusive results in this time-frame. There is no difference in weight loss between the exercise and no exercise groups, though there is a decrease in fat mass and an increase in lean body mass in exercisers $(P<.05)$.
Five studies examine the association of exercise on postoperative weight loss past 1 year. Wolfe et al. found a correlation between exercise and BMI change for all patients at 24 months, though there is no significant difference in BMI change between exercisers versus nonexercisers $(P>0.06)$. Bond et al. [10] report that active patients lose more weight than those who are sedentary 24 month after surgery. This is consistent when patients are separated into groups according to preoperative BMI (3549 versus $50-70$ ). Results are similar for Latner et al., with the additional finding that proximity to goal weight correlates with postoperative exercise frequency $(r=0.345$, $P<0.02)$. Bueter et al. report a correlation between exercise and successful weight loss, while a lack of postoperative exercise is a predictor of failure $(\% \mathrm{EWL}<20$ or band removal) (relative risk 4.0, $P=0.045$ ). Larsen et al. is the only study to find no evidence of a beneficial association of physical activity at 24 months after bariatric surgery, despite their use of a validated instrument.

The majority of the studies only include patients undergoing RYGB. The six studies that did not specify whether RYGB was performed laparoscopically or through an open technique all report a positive association between 


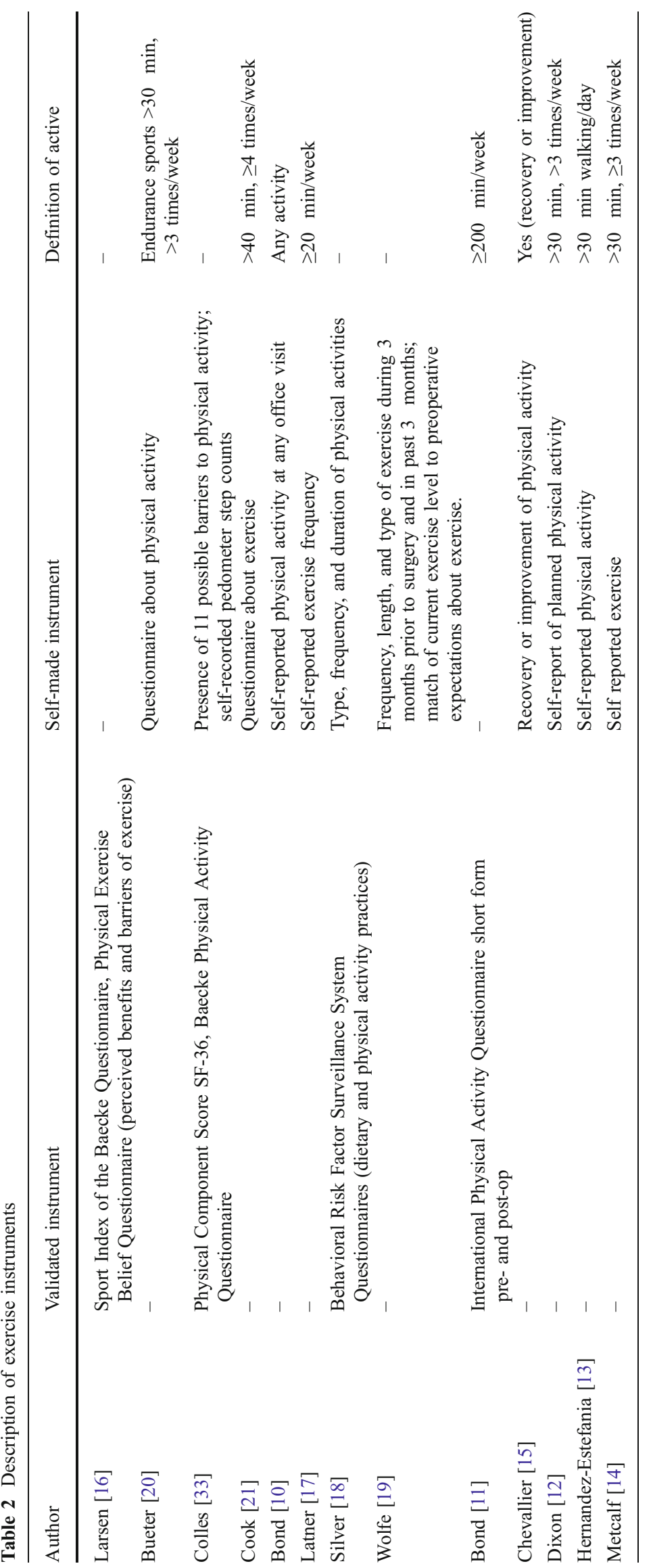


Table 3 Association of exercise on postoperative weight loss

\begin{tabular}{|c|c|c|c|c|c|}
\hline Author & $\begin{array}{l}\mathrm{F} / \mathrm{U} \\
(\mathrm{mo})\end{array}$ & Groups $(\mathrm{N})$ & $\begin{array}{l}\text { Mean weight } \\
\text { loss }\end{array}$ & Results (correlation) & Association \\
\hline Colles [33] & 12 & $-(129)$ & $50(20.7)^{\mathrm{b}}$ & $\begin{array}{l}\text { Baecke Leisure Index Score and \% weight } \\
\text { loss }\left(r=0.32^{* * *}\right) \text {; change in Leisure Index }\left(r=0.33^{* * *}\right) \\
\text { and Baecke Total Score }\left(r=0.21^{*}\right) \text { and } \% \mathrm{WL} \text {; minimum } \\
\text { pedometer stepcount and } \% \mathrm{WL}\left(r=0.3^{*}\right)\end{array}$ & Positive \\
\hline Chevallier [15] & 12 & $\begin{array}{l}\text { Inactive }(619) \\
\text { Active }(303)\end{array}$ & $\begin{array}{l}23.8 \% \%^{\mathrm{c}} \\
42 \% * * *\end{array}$ & $\begin{array}{l}\text { Post-op physical activity and chance of }>50 \% \text { excess } \\
\text { weight loss }\left(\mathrm{OR} 2.3^{* *}\right)\end{array}$ & Positive \\
\hline $\begin{array}{l}\text { Hernandez-Estefania } \\
\text { [13] }\end{array}$ & 12 & $\begin{array}{l}\text { Inactive } \\
\text { Active (67) }\end{array}$ & $\begin{array}{l}12.5^{\mathrm{d}} \\
16.5^{* * *}\end{array}$ & - & Positive \\
\hline Cook [21] & 12 & $\begin{array}{l}\text { Success } \\
\text { Failure (100) }\end{array}$ & $\begin{array}{ll}28-92 & \mathrm{~kg} \\
22-87 & \mathrm{~kg}\end{array}$ & Post-op exercise and successful weight loss & Positive \\
\hline Metcalf [14] & 12 & $\begin{array}{l}\text { Exercise }(50) \\
\text { No exercise }(50)\end{array}$ & $\begin{array}{l}58 \% \\
57 \%{ }^{\mathrm{f}}\end{array}$ & No difference in BMI between exercisers and non-exercisers & Inconclusive \\
\hline Bond [11] & 12 & $\begin{array}{l}\text { Inact/inact }^{\mathrm{a}}(39) \\
\text { Inact/act (83) } \\
\text { Act/Act (68) }\end{array}$ & $\begin{array}{l}63.1(16.6)^{\mathrm{b}} \\
71.5(15.5) \\
69.8(14.1)^{*}\end{array}$ & Change in physical activity and weight loss $\left(\rho=-0.15^{*}\right)$ & Positive \\
\hline Latner [17] & 16 & $-(65)$ & $71 \%{ }^{\mathrm{e}}$ & Post-op exercise frequency and BMI change $(B=0.29 * *)$ & Positive \\
\hline Wolfe [19] & 20 & $-(194)$ & - & Increase in exercise and BMI change $\left(r=0.36^{* *}\right)$ & Positive \\
\hline Bond [10] & 24 & $\begin{array}{l}\text { Sedentary }(106) \\
\text { Active }(1,479)\end{array}$ & $\begin{array}{l}63.9(19.5)^{\mathrm{b}} \\
68.2(17.4)^{* *}\end{array}$ & - & Positive \\
\hline Silver [18] & 24 & $-(140)$ & $55.8(15.2) \mathrm{kg}$ & $\begin{array}{l}\text { Post-op physical activity (min/episode) and } \\
\text { post-op BMI }\left(\mathrm{OR}=-.15^{*}\right)\end{array}$ & Positive \\
\hline Dixon [12] & 24 & $\begin{array}{l}\text { Inactive (30) } \\
\text { Active }(30)\end{array}$ & $\begin{array}{l}7.8(12.3) \mathrm{kg} \\
13.9(10.9) \mathrm{kg} *\end{array}$ & $\begin{array}{l}\text { Average times participants reported performing planned } \\
\text { physical activity each week and weight loss }\left(r=0.39^{* *}\right)\end{array}$ & Positive \\
\hline Larsen [16] & 24 & $-(157)$ & $10.2^{\mathrm{d}}$ & No association between exercise and weight outcome & $\begin{array}{l}\text { No } \\
\text { association }\end{array}$ \\
\hline Bueter [20] & 27 & $-(85)$ & $43.2^{\mathrm{b}}$ & $\begin{array}{l}\text { Post-op exercise and successful weight loss }(\% \mathrm{EWL}>50 \\
\left.\text { with no band removal) (RR } 4.2^{* *}\right)\end{array}$ & Positive \\
\hline
\end{tabular}

$W L$ weight loss, $O R$ odds ratio, $R R$ relative risk; inact inactive, act active

$* P<0.05 ; * * P<0.01 ; * * * P<0.001$

${ }^{\text {a }}$ Preoperative/postoperative

b $\%$ EWL

${ }^{\mathrm{c}} \%$ patients with EWL $>50 \%$

${ }^{\mathrm{d}}$ BMI points lost

${ }^{\mathrm{e}}$ EWL based on BMI change

${ }^{\mathrm{f}}$ Total \% BMI change

exercise and postoperative weight loss. Of the three studies that specified laparoscopic RYGB, two found a positive association while one did not. The two LAGB studies and the VBG study also found a positive result, while the duodenal switch study was inconclusive. The three prospective cohort studies, which include a mix of bariatric procedures, report a positive association between exercise and weight loss.

\section{Postoperative Weight Loss: Meta-analysis}

A meta-analysis of postoperative weight loss at 12 months assessed the association of exercise versus no exercise (Fig. 2). The included studies report postoperative weight loss as percentage of total BMI change. The studies included RYGB, VBG, and DS, respectively. The exercise group overall lost a mean of $4.2 \%$ greater total BMI $(95 \%$ CI $(0.3$ to $8.1 \%))$. There was no significant heterogeneity $(P=0.34)$.

\section{Discussion}

Eleven of the thirteen studies reported that exercise and physical activity correlate with greater postoperative weight loss following bariatric surgery. Meta-analysis suggests $4.2 \%$ greater degree of weight loss (total BMI) at 12 months, and greater weight loss persists out to 


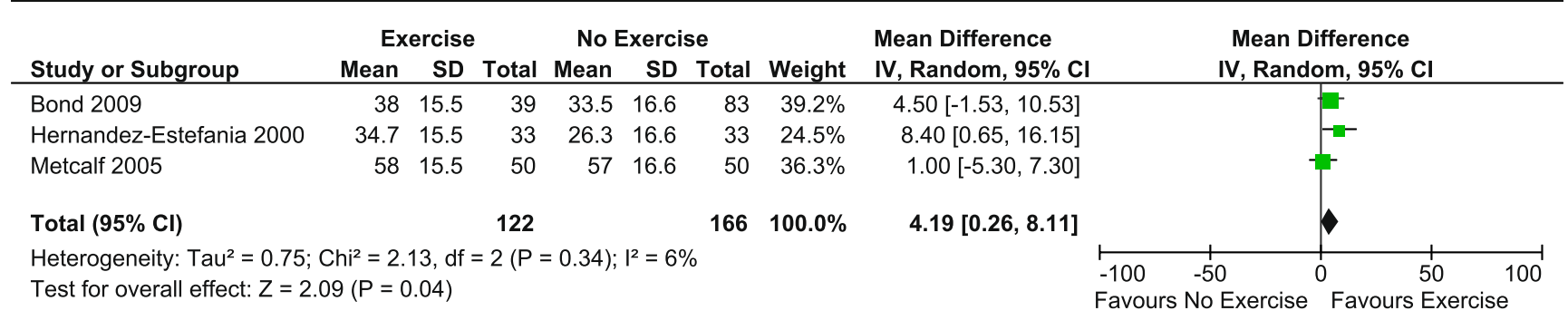

Fig. 2 Meta-analyses of postoperative weight loss at 12 months for exercise versus no exercise groups. Forest plots of random-effects metaanalyses of \% total BMI loss at 12 months, separately for exercise versus no exercise groups

24 months. There is significant variation in how exercise is defined, with few studies using validated surveys and none that are specific to bariatric surgery patients. Standard guidelines for appropriate amount of exercise for bariatric patients still need to be developed.

There is great variation in how exercise is measured and the minimal threshold to define a physically active patient. Of the two studies that found inconclusive results, Larsen et al. used the Sport Index of the Baecke Questionnaire and report that exercise levels may be too low after gastric bypass to contribute to weight loss. The Sport Index may not be appropriate to measure physical activity in this population. Metcalf et al. found no association between physical activity and EWL but there is a benefit in lean body mass.

The definition of an active patient differs among studies, but four studies require at least 30 minutes of exercise on 3 or more days per week. Three studies require from 20 to 200 minutes per week. However, only Bueter et al. and Hernandez-Estefania et al. specify the type of activity to be endurance sports and walking, respectively, while the remainder do not state a lower limit of what is accepted as exercise.

An appropriate definition of exercise should include the weekly duration as well as the type of activities performed. There are few validated instruments used in the bariatric literature to measure activity levels, and all are based on self-reporting. The two most relevant surveys reported in this review are the Baecke Physical Activity Questionnaire and the International Physical Activity Questionnaire. In a recent review of studies assessing physical activity in cardiac patients, the two most frequently used instruments are the Baecke Questionnaire and the Stanford 7-Day Physical Activity Recall [27]. The latter has measures for sleep and moderate, hard, or very hard physical activity carried out in the past 7 days. Though it is the most commonly used survey in the cardiac population, it has low validity in women and was assessed to be not suitable for cardiac patients. There is no single instrument that is accepted as the gold standard for measuring exercise in bariatric patients. However, the use of a standardized and validated survey would allow for comparing and/or pooling between future studies.

There are no standardized guidelines for how much exercise is appropriate for the postoperative bariatric surgery patient. Some recommendations suggest that daily walking is adequate and pedometers are useful to help track activity [28]. Others recommend a minimum accumulation of weekly activity points (200 to 300 points), based on what activities are performed (e.g. walking, bicycling, housekeeping, or sports) and for what duration [29]. This method roughly correlates with the IPAQ score. Encouraging 30-45 minutes of physical activity of moderate intensity (e.g. walking) for 3 to 5 days per week has also been reported [30]. This is the recommendation that is most commonly given in the studies included in this review. It also closely parallels the American Heart Association / American College of Sports Medicine guidelines on physical activity, which include 30 minutes of moderate-intensity aerobic activity on five days each week or 20 minutes of vigorousintensity activity for three days each week [31].

Motivating patients to exercise can be difficult, especially in the bariatric population. Counseling that begins preoperatively can help prepare patients for the physical activity that will be recommended after surgery. Instruction to walk, which is low-impact and already done to some degree by the majority of people, may increase compliance. Pedometers are a good motivational tool to encourage patients to fulfill set goals. Finally, barriers to exercise (e.g. health concerns, lack of proximity to a gym or park, feeling self-conscious) should be identified and minimized if possible. Screening patients for low physical activity can help to identify those who may need additional help and need targeted interventions to help them achieve optimal weight loss.

Though most studies report a positive association between physical activity and postoperative weight loss, this does not prove that exercise causes more weight loss after bariatric surgery. Patients who lose more weight may feel better physically and this can lead them to exercise more. A randomized trial or matched cohort would help demonstrate whether a causal relationship exists. 
This review has some limitations mainly related to the heterogeneity of the studies. The variations in defining exercise and how it is measured made it difficult to compare the studies. Furthermore, the majority of studies did not report patient follow-up or actual compliance with exercise activities. This limits the validity of their findings and makes it challenging to identify the most successful exercise regiment for this patient population. Degree of weight loss is also reported in different ways, with some studies reporting kilograms or BMI points lost while others include the percentage of excess weight loss. In addition, little data is reported on the association of other patient factors, such as race, gender, or age, on the correlation between exercise and weight loss. The level of physical activity may differ according to baseline patient characteristics, with one study finding that women exercise more than men postoperatively [32]. Targeting certain patients groups may be useful if they are found to benefit more from exercise.

In summary, postoperative exercise is associated with greater weight loss at 12 and 24 months after bariatric surgery. The long-term benefit of exercise in this patient population remains to be shown. Further studies are necessary to determine the appropriate recommendations for the minimum level of physical activity, as well as the best instruments for exercise in the bariatric population.

Acknowledgements We would like to acknowledge the generous contribution of Paul G. Shekelle to the design of our project and critical review of the analysis. The VA Department of Surgery provided support for Dr. Livhits and Dr. Maggard. Dr. Maggard's time was supported in part by a grant from the Robert Wood Johnson Physician Faculty Scholars program.

Disclosures None

Financial Support VA Department of Surgery. Robert Wood Johnson Physician Faculty Scholars program

Conflict of Interest The authors declare that they have no conflict of interest.

Open Access This article is distributed under the terms of the Creative Commons Attribution Noncommercial License which permits any noncommercial use, distribution, and reproduction in any medium, provided the original author(s) and source are credited.

\section{References}

1. Wandell PE, Carlsson AC, Theobald H. The association between BMI value and long-term mortality. Int J Obes (Lond). 2009;33 (5):577-82.

2. Hainer V, Toplak H, Mitrakou A. Treatment modalities of obesity: what fits whom? Diabetes Care. 2008;31 Suppl 2:S269-77.
3. Wei M, Kampert JB, Barlow CE, et al. Relationship between low cardiorespiratory fitness and mortality in normal-weight, overweight, and obese men. JAMA. 1999;282:1547-53.

4. Noel PH, Pugh JA. Management of overweight and obese adults. BMJ. 2002;325:757-61.

5. Hagan RD, Upton SJ, Wong L, et al. The effects of aerobic conditioning and/or caloric restriction in overweight men and women. Med Sci Sports Exerc. 1986;18:87-94.

6. Ross R, Dagnone D, Jones PJ, et al. Reduction in obesity and related comorbid conditions after diet-induced weight loss or exercise-induced weight loss in men. A randomized, controlled trial. Ann Intern Med. 2000;133:92-103.

7. Fogelholm M, Kukkonen-Harjula K. Does physical activity prevent weight gain-a systematic review. Obes Rev. 2000;1:95-111.

8. Okay DM, Jackson PV, Marcinkiewicz M, et al. Exercise and obesity. Prim Care. 2009;36:379-93.

9. Review Manager (RevMan) [Computer program]. Version 5.0. Copenhagen: The Nordic Cochrane Centre TCC2.

10. Bond DS, Evans RK, Wolfe LG, et al. Impact of self-reported physical activity participation on proportion of excess weight loss and BMI among gastric bypass surgery patients. Am Surg. 2004;70:811-4.

11. Bond DS, Phelan S, Wolfe LG, et al. Becoming physically active after bariatric surgery is associated with improved weight loss and health-related quality of life. Obesity (Silver Spring). 2009;17:78-83.

12. Dixon JB, O'Brien PE, Playfair J, et al. Adjustable gastric banding and conventional therapy for type 2 diabetes: a randomized controlled trial. JAMA. 2008;299:316-23.

13. Hernandez-Estefania R, Gonzalez-Lamuno D, Garcia-Ribes M, et al. Variables affecting BMI evolution at 2 and 5 years after vertical banded gastroplasty. Obes Surg. 2000;10:160-6.

14. Metcalf B, Rabkin RA, Rabkin JM, et al. Weight loss composition: the effects of exercise following obesity surgery as measured by bioelectrical impedance analysis. Obes Surg. 2005; 15:183-6.

15. Chevallier JM, Paita M, Rodde-Dunet MH, et al. Predictive factors of outcome after gastric banding: a nationwide survey on the role of center activity and patients' behavior. Ann Surg. 2007;246:1034-9.

16. Larsen JK, Geenen R, van Ramshorst B, et al. Binge eating and exercise behavior after surgery for severe obesity: a structural equation model. Int J Eat Disord. 2006;39:369-75.

17. Latner JD, Wetzler S, Goodman ER, et al. Gastric bypass in a lowincome, inner-city population: eating disturbances and weight loss. Obes Res. 2004;12:956-61.

18. Silver HJ, Torquati A, Jensen GL, et al. Weight, dietary and physical activity behaviors two years after gastric bypass. Obes Surg. 2006;16:859-64.

19. Wolfe BL, Terry ML. Expectations and outcomes with gastric bypass surgery. Obes Surg. 2006;16:1622-9.

20. Bueter $M$, Thalheimer $A$, Lager $C$, et al. Who benefits from gastric banding? Obes Surg. 2007;17:1608-13.

21. Cook CM, Edwards C. Success habits of long-term gastric bypass patients. Obes Surg. 1999;9:80-2.

22. Westerterp KR. Assessment of physical activity level in relation to obesity: current evidence and research issues. Med Sci Sports Exerc. 1999;31:S522-5.

23. Ono R, Hirata S, Yamada M, et al. Reliability and validity of the Baecke physical activity questionnaire in adult women with hip disorders. BMC Musculoskelet Disord. 2007;8:61.

24. Baecke JA, Burema J, Frijters JE. A short questionnaire for the measurement of habitual physical activity in epidemiological studies. Am J Clin Nutr. 1982;36:936-42.

25. Tehard B, Saris WH, Astrup A, et al. Comparison of two physical activity questionnaires in obese subjects: the NUGENOB study. Med Sci Sports Exerc. 2005;37:1535-41. 
26. Craig CL, Marshall AL, Sjostrom M, et al. International physical activity questionnaire: 12-country reliability and validity. Med Sci Sports Exerc. 2003;35:1381-95.

27. Le Grande MR, Elliott PC, Worcester MU, et al. An evaluation of self-report physical activity instruments used in studies involving cardiac patients. J Cardiopulm Rehabil Prev. 2008; 28:358-69.

28. Petering R, Webb CW. Exercise, fluid, and nutrition recommendations for the postgastric bypass exerciser. Curr Sports Med Rep. 2009;8:92-7.

29. Ehrsam R, Stoffel S, Koerner U, et al. Exercise prescription for the overweight and the obese: how to quantify and yet keep it simple. Br J Sports Med. 2009;43:951-3.
30. Poirier P, Despres JP. Exercise in weight management of obesity. Cardiol Clin. 2001;19:459-70.

31. Haskell WL, Lee IM, Pate RR, et al. Physical activity and public health: updated recommendation for adults from the American College of Sports Medicine and the American Heart Association. Circulation. 2007;116:1081-93.

32. Buddeberg-Fischer B, Klaghofer R, Krug L, et al. Physical and psychosocial outcome in morbidly obese patients with and without bariatric surgery: a 4 1/2-year follow-up. Obes Surg. 2006; $16: 321-30$.

33. Colles SL, Dixon JB, O'Brien PE. Hunger control and regular physical activity facilitate weight loss after laparoscopic adjustable gastric banding. Obes Surg. 2008;18:833-40. 